\title{
Open Posterior Approach versus Arthroscopic Suture Fixation for Displaced Posterior Cruciate Ligament Avulsion Fractures: Systematic Review
}

\author{
Jae-Gwang Song, $\mathrm{MD}^{1}$, Kyung-Wook Nha, $\mathrm{MD}^{2}$, and Se-Won Lee, $\mathrm{MD}^{3}$ \\ ${ }^{1}$ Department of Orthopedic Surgery, Suncheon Joongang Hospital, Suncheon; ${ }^{2}$ Department of Orthopedic Surgery, Ilsan Paik Hospital, College of Medicine, Inje \\ University College of Medicine, Goyang; ${ }^{3}$ Department of Orthopedic Surgery, Yeouido St. Mary’s Hospital, College of Medicine, The Catholic University of Korea, Seoul, \\ Korea
}

\begin{abstract}
Purpose: To compare the clinical outcomes between the open posterior approach and arthroscopic suture fixation for displaced posterior cruciate ligament (PCL) avulsion fractures.

Methods: A literature search was performed on MEDLINE, EMBASE, and the Cochrane Library databases. The inclusion criteria were as follows: papers written in English on displaced PCL avulsion fractures, clinical trial(s) with clear description of surgical technique, adult subjects, a follow-up longer than 12 months and modified Coleman methodology score (CMS) more than 60 points.

Results: Twelve studies were included with a mean CMS value of 72.4 (standard deviation, 7.6). Overall, 134 patients underwent the open posterior approach with a minimum 12-month follow-up, and 174 patients underwent arthroscopic suture fixation. At final follow-up, the range of Lysholm score was 85-100 for the open approach and 80-100 for the arthroscopic approach. Patients who were rated as normal or nearly normal in the International Knee Documentation Committee subjective knee assessment were $92 \%-100 \%$ for the open approach and $90 \%-100 \%$ for the arthroscopic approach. The range of side-to-side difference was $0-5 \mathrm{~mm}$ for both approaches.

Conclusions: Both arthroscopic and open methods for the treatment of PCL tibial-side avulsion injuries resulted in comparably good clinical outcomes, radiological healing, and stable knees.
\end{abstract}

Keywords: Knee, Posterior cruciate ligament, Avulsion, Arthroscopy, Open

\section{Introduction}

The posterior cruciate ligament (PCL) is an important structure that helps to maintain the stability of the knee during flexion and rotation. Since the PCL is strong, avulsion fractures at the attachment site of PCL occur commonly. It is generally agreed that

Received October 3, 2017; Revised February 28, 2018;

Accepted May 27, 2018

Correspondence to: Se-Won Lee, MD

Department of Orthopedic Surgery, Yeouido St. Mary's Hospital, College of Medicine, The Catholic University of Korea, 63-ro 10, Yeongdeungpogu, Seoul 07345, Korea

Tel: +82-2-3779-1068, Fax: +82-2-783-0252

E-mail: ssewon@naver.com

This is an Open Access article distributed under the terms of the Creative Commons Attribution Non-Commercial License (http://creativecommons.org/licenses/by-nc/4.0/) which permits unrestricted non-commercial use, distribution, and reproduction in any medium, provided the original work is properly cited. avulsion fractures of the PCL should be anatomically reduced and fixed for complete restoration of PCL function ${ }^{1)}$.

In most cases, conservative treatments lead to unsatisfactory results mainly due to functional disability and fracture nonunion ${ }^{2}$. Many surgeons believe the displaced or unstable tibial avulsion fracture of PCL should be reduced and fixed anatomically through surgeries with various techniques ${ }^{3)}$. Surgical treatments for PCL avulsion fractures of the tibia include arthroscopic repair as well as open reduction and internal fixation. Open reduction and fixation through the traditional posterior approach is technically easier than arthroscopic surgery, does not have requirement for specialized equipment, has a relatively short learning curve ${ }^{4)}$; whereas it has a potential risk of significant soft tissue damage and neurovascular damage, as the tibial attachment of PCL is located in an area difficult to access ${ }^{5}$. Recently, due to its deep location and the complexity of the adjacent anatomy, minimally invasive arthroscopic techniques are gaining interest ${ }^{6)}$. The additional 
advantages of the arthroscopic approach are direct visualization of fragment reduction and concomitant intra-articular injuries in the form of meniscal tears; further, osteochondral loose fragments or ligament injuries may be addressed at the time of the operation $^{5-10)}$. Despite comparable biomechanical properties of open and arthroscopic techniques ${ }^{11)}$, there is a paucity of comparative clinical studies (open vs. arthroscopic) in the literature.

The present systematic review was conducted to compare the clinical outcomes between open reduction and screw fixation and arthroscopic suture fixation for displaced tibial PCL avulsion fractures. Our initial hypothesis was that arthroscopic suture fixation would provide superior outcomes with less complications.

\section{Materials and Methods}

\section{Search Strategy}

Two of the authors (JGS and SWL) independently performed comprehensive online literature searches of the MEDLINE, EMBASE, and Cochrane Library databases between May 10, 2016 and May 20, 2016. For each database, search formula was modified individually. Database search terms included "posterior cruciate ligament" OR "PCL" AND "fracture" OR "tibia" OR “avulsion(s)" OR "bone” OR "arthroscopic" OR “open” OR "approach" OR "surgical" OR "fixation". The same 2 authors independently screened the title and abstract of each returned article and then reviewed the full text of each article that had been selected on the basis of the inclusion and exclusion criteria (Table 1). In the case of two or more studies by the same author, we determined whether the patients were duplicated or not. If duplicated, we included only the study with a longer follow-up period. Reference lists and bibliographies of the selected articles were also reviewed additionally.

\section{Quality Assessment}

The methodological quality of each of the studies included in the analysis was evaluated by 2 of the authors individually according to the Coleman methodology score ${ }^{12}$. Each study was assessed for each of the methodology's 10 criteria, resulting in a final score ranging anywhere from 0 to 100 . A perfect score of 100 indicated a study design that largely avoids the influence of chance, various biases, and confounding factors. Each author scored the methodological quality of the studies twice with a 10day interval between assessments. In the case of disagreement, the 2 authors debated the controversial score until reaching a consensus. To ensure the reliability of reported findings, data were extracted only from studies with $\geq 60$ points Coleman score.

\section{Data Abstraction}

The studies were evaluated by 2 authors (JGS and SWL) for methodological quality. To extract data from the papers, we used a standardized form including the following items: first author, publication year, publishing journal, study type, demographic factors, sample sizes, and results of research. Data were then extracted and crosschecked for accuracy. Subjects in the studies were divided into 2 treatment groups: those undergoing the open posterior approach and those undergoing arthroscopic fixation. Study data including (1) demographic data of patients (including age and sex distribution), (2) time to operation, (3) associated injuries, (4) surgical approach, (5) fixation method (suture, screw, or any device), and (6) follow-up are summarized in Table 2. The clinical outcome data extracted from studies included (1) overall clinical results, (2) remained instability, and (3) complications, as summarized in Table 3 . The clinical outcome measures specifically recorded in all included studies were (1) Lysholm score at final follow-up, (2) International Knee Documentation

Table 1. Inclusion and Exclusion Criteria

\begin{tabular}{ll}
\hline \multicolumn{1}{c}{ Inclusion criteria } & \multicolumn{1}{c}{ Exclusion criteria } \\
\hline $\begin{array}{l}\text { Studies with patients who received isolated fixation or suturing } \\
\text { for displaced posterior cruciate ligament tibial avulsion using } \\
\text { arthroscopic/open approach }\end{array}$ & $\begin{array}{c}\text { Studies with patients with: } \\
\text { (1) Dislocated knee with posterior cruciate ligament tibial avulsion }\end{array}$ \\
Minimum follow-up period, 1 year & (2) A history of previous surgery \\
Between level I and level IV studies & (3) Conservative treatment \\
Human in vivo study & (4) Nonunion or delayed union of tibial avulsion of posterior cruciate \\
Articles written in English & ligament \\
& Sample size less than 5 patients \\
& Lack of description of outcomes measurement \\
& Level V evidence (case report, technical note, letter to editor), \\
& biomechanical reports, and review articles
\end{tabular}


Table 2. Patients' Demographic Information and Surgical Procedure

\begin{tabular}{|c|c|c|c|c|c|c|c|c|c|c|}
\hline Study & $\begin{array}{l}\text { No. of } \\
\text { patients }\end{array}$ & $\begin{array}{c}\text { Sex } \\
(\mathrm{M} / \mathrm{F})\end{array}$ & $\begin{array}{c}\text { Mean } \\
\text { age } \\
(\mathrm{yr}) \\
\end{array}$ & $\begin{array}{c}\text { Time to } \\
\text { operation } \\
\text { (day) }\end{array}$ & $\begin{array}{l}\text { Associated } \\
\text { injuries }\end{array}$ & $\begin{array}{l}\text { Operative } \\
\text { time (min) }\end{array}$ & $\begin{array}{l}\text { Surgical } \\
\text { approach }\end{array}$ & $\begin{array}{l}\text { Fixation } \\
\text { device }\end{array}$ & $\begin{array}{l}\text { fragment } \\
\text { size }\end{array}$ & $\begin{array}{l}\text { Follow-up } \\
\text { (mo) }\end{array}$ \\
\hline \multicolumn{11}{|l|}{ Posterior open approach } \\
\hline Singer and Halawa ${ }^{15)}$ & 16 & $16 / 0$ & 34.5 & 8 & Excluded & $32(25-40)$ & $\begin{array}{l}\text { Modified posteromedial } \\
\text { approach (medial } \\
\text { head of gastrocnemius } \\
\text { was split) }\end{array}$ & $\begin{array}{l}\text { Pull out suture using } \\
\text { Ethibond }\end{array}$ & & $18(12-28)$ \\
\hline Chen et al. ${ }^{13)}$ & 24 & $15 / 9$ & 35.8 & 2 to 7 & $\begin{array}{l}\text { Injuries in } \\
\text { other } \\
\text { ligaments } \\
\text { and menisci } \\
\text { (6) }\end{array}$ & 52.5 & $\begin{array}{l}\text { Minimally invasive } \\
\text { posterior approach } \\
\text { (macroendoscopic } \\
\text { technique) }\end{array}$ & $\begin{array}{l}\text { Cannulated screw } \\
\text { fixation }\end{array}$ & $\begin{array}{l}\text { 8-12 mm: } 7 \\
12-26 \mathrm{~mm}: 11 \\
\text { Comminuted fracture } \\
\text { with two fragments } \\
\text { over } 8 \mathrm{~mm}\end{array}$ & $33.6(24-60)$ \\
\hline Inoue et al. ${ }^{14)}$ & $\begin{array}{l}16 \text { (excluding } \\
\text { PCL injuries } \\
\text { without bony } \\
\text { involvement) }\end{array}$ & $6 / 25$ & 44 & $\begin{array}{l}7.2 \text { days in } \\
\text { group } \mathrm{O} ; \\
8.3 \text { days in } \\
\text { group } \mathrm{N}\end{array}$ & Excluded & N/A & $\begin{array}{l}\text { Traditional posterior } \\
\text { approach and post- } \\
\text { eromedial approach } \\
\text { (the proportion was } \\
\text { not presented) }\end{array}$ & $\begin{array}{l}\text { Cannulated cancellous } \\
\text { screws with a washer }\end{array}$ & $\begin{array}{l}\text { The size of the } \\
\text { fragments was } \\
1.5 \times 1.5 \mathrm{~cm} \text { or } \\
\text { greater. }\end{array}$ & $36(24-96)$ \\
\hline Yang et al. ${ }^{4)}$ & $\begin{array}{l}16 \text { (including } \\
2 \text { chronic } \\
\text { cases) }\end{array}$ & $10 / 6$ & 28 & $\begin{array}{l}<2 \text { weeks } \\
\text { in } 14 ;>4 \\
\text { weeks in } 2\end{array}$ & $\begin{array}{l}\text { LCL injury (1), } \\
\text { ACL injury } \\
\text { (1), } \\
\text { medial } \\
\text { meniscus } \\
\text { injury (1) }\end{array}$ & N/A & $\begin{array}{l}\text { Traditional posterior } \\
\text { approach }\end{array}$ & $\begin{array}{l}\text { 14: malleolar screw } \\
\text { 2: pull out screw due } \\
\text { to small fragment } \\
\text { size }\end{array}$ & $\begin{array}{l}\text { N/A, but it was } \\
\text { recorded that } 2 / 16 \\
\text { was fixed with } \\
\text { pullout suture due to } \\
\text { small fragment size }\end{array}$ & $38(24-58)$ \\
\hline Chiarapattanakom et al. ${ }^{3)}$ & 10 & $6 / 4$ & 30 & 10 & Excluded & N/A & Posteromedial approach & $\begin{array}{l}\text { Unicortical cancellous } \\
\text { screw fixation. } \\
\text { If fragment size was } \\
\text { small, spike washer } \\
\text { was added. }\end{array}$ & N/A & $40(22-58)$ \\
\hline \multicolumn{11}{|l|}{ Arthroscopic approach } \\
\hline Zhao et al. ${ }^{7}$ & 29 & $21 / 8$ & 32 & 12 & Excluded & $55(45-75)$ & $\begin{array}{l}\text { Pullout suture using } \\
\text { Y-shaped bone tunnel } \\
\text { and titanium button }\end{array}$ & $\begin{array}{l}2 \text { No. } 6 \text { polyester } \\
\text { sutures }\end{array}$ & N/A & $32(24-41)$ \\
\hline Huang et al. ${ }^{5)}$ & 18 & $13 / 5$ & 28 & 4.8 & N/A & $35(21-55)$ & $\begin{array}{l}\text { Anterior arthroscopy } \\
\text { assisted fixation } \\
\text { guided with a tibial } \\
\text { PCL guide }\end{array}$ & $\begin{array}{l}\text { One or two antegrade } \\
\text { screws }\end{array}$ & $\begin{array}{l}\text { Inclusion: the fracture } \\
\text { fragment size was } \\
\text { greater than } 20 \mathrm{~mm}\end{array}$ & $34(24-49)$ \\
\hline Gui et al. $^{8)}$ & 28 & $19 / 9$ & 35.3 & 3.4 & $\begin{array}{c}\text { LCL (1), MM } \\
(4), \text { LM (4), } \\
\text { MCL (1) }\end{array}$ & $67(45-90)$ & $\begin{array}{l}\text { Pullout suture using } \\
\text { single tunnel }\end{array}$ & PDS & $\begin{array}{l}20 \text { single fragment } \\
\text { (mean, } 16 \mathrm{~mm}) \\
8 \text { comminution } \\
\text { (largest fragment, } \\
<10 \mathrm{~mm} \text { ) }\end{array}$ & $40(26-61)$ \\
\hline Chen et al. ${ }^{9)}$ & 36 & $24 / 12$ & 35.6 & 5 & $\begin{array}{l}\mathrm{LM}(2), \mathrm{MM} \\
\quad(3), \operatorname{MCL}(2), \\
\text { LCL (2) }\end{array}$ & N/A & $\begin{array}{l}\text { Pullout suture using } \\
\text { double tunnel }\end{array}$ & No. 5 Ethibond & $\begin{array}{l}\text { Various } \\
\text { fragmentation sizes } \\
(\text { range, } 10 \times 6 \times 5 \text { to } \\
30 \times 32 \times 15 \mathrm{~mm} \text {; } \\
\text { mean, } 15 \times 17 \times 9 \\
\mathrm{~mm})\end{array}$ & $36(24-45)$ \\
\hline Chen et al. ${ }^{10)}$ & 22 & $20 / 2$ & 37 & 13 & N/A & 70.5 & $\begin{array}{l}\text { Pullout suture using } \\
\text { double tunnel }\end{array}$ & No. 5 Ethibond & N/A & $24.5(19-28)$ \\
\hline \multicolumn{11}{|l|}{ Comparative study } \\
\hline Open & 27 & $25 / 2$ & 28.4 & 6.2 & $\begin{array}{l}\text { MCL (2), LCL } \\
\quad(2)\end{array}$ & N/A & $\begin{array}{l}\text { Modified posteromedial } \\
\text { approach (medial } \\
\text { head of gastrocnemius } \\
\text { was split) }\end{array}$ & $\begin{array}{l}\text { Partial threaded } \\
\text { cannlated screw and } \\
\text { washer }\end{array}$ & N/A & 12 \\
\hline Arthroscopic & 20 & $18 / 2$ & 26.6 & 8.4 & $\begin{array}{l}\text { MCL (1), LCL } \\
\text { (1), LM (1), } \\
\text { MM (2), } \\
\text { ACL (6) }\end{array}$ & N/A & $\begin{array}{l}\text { Single tunnel pullout } \\
\text { suture }\end{array}$ & $\begin{array}{l}\text { No. } 2 \text { Orthocord, tied } \\
\text { over suture disk }\end{array}$ & N/A & 12 \\
\hline \multicolumn{11}{|l|}{ Pardiwala et al. ${ }^{16)}$} \\
\hline Open & 25 & N/A & N/A & N/A & N/A & N/A & Posteromedial approach & $\begin{array}{l}4 \text { mm cannulated } \\
\text { cancellous screw } \\
\text { and washer or No. } 5 \\
\text { Ethibond (fragment } \\
\text { size: small or } \\
\text { comminuted) }\end{array}$ & N/A & $39(24-58)$ \\
\hline Arthroscopic & 25 & N/A & N/A & N/A & N/A & N/A & $\begin{array}{l}\text { Pullout suture using } \\
\text { double tunnel }\end{array}$ & $\begin{array}{l}\text { No. } 5 \text { Ethibond or } \\
\text { No. } 2 \text { Fiberwire }\end{array}$ & N/A & $39(24-58)$ \\
\hline
\end{tabular}

Values are presented as mean (range or standard deviation).

PCL: posterior cruciate ligament, N/A: not available, LCL: lateral collateral ligament, MM: medial meniscus, LM: lateral meniscus, MCL: medial collateral ligament, ACL: anterior cruciate ligament. 
Table 3. Overall Clinical Outcomes and Complications in Studies

\begin{tabular}{|c|c|c|c|c|c|c|c|c|c|c|c|c|c|}
\hline \multirow{2}{*}{ Study } & \multirow{2}{*}{$\begin{array}{l}\text { No. of } \\
\text { patients }\end{array}$} & \multicolumn{2}{|c|}{ IKDC } & \multicolumn{2}{|c|}{ Lysholm } & \multicolumn{2}{|c|}{ Postop draw test } & \multicolumn{2}{|c|}{ Stress X-ray } & \multicolumn{2}{|c|}{ KT } & \multirow{2}{*}{ Complication } & \multirow{2}{*}{ Etc. } \\
\hline & & Preop & Postop & Preop & Postop & Preop & Postop & Preop & Postop & Preop & Postop & & \\
\hline \multicolumn{14}{|l|}{ Open } \\
\hline Singer and & 16 & & Grade A: 13 & & $92-100$ & Grade 2: 10 & Grade 1: 1 & & & & & & \\
\hline Halawa $^{15)}$ & & & Grade B: 3 & & & Grade 3: 6 & Negative: 15 & & & & & & \\
\hline \multirow[t]{3}{*}{ Chen et al. ${ }^{13)}$} & 24 & & Grade A: 17 & 43.8 & 95.3 & & Grade 1: 1 & & & & $0.6-4.0$ & & \\
\hline & & & Grade B: 6 & & & & Negative: 23 & & & & & & \\
\hline & & & Grade C: 1 & & & & & & & & & & \\
\hline Inoue et al. ${ }^{14)}$ & 16 & & & & $85-100$ & & & & & & $0-5$ & & \\
\hline Yang et al. ${ }^{4}$ & 16 & & & & & & & & & & & $\begin{array}{l}\text { Deep infection: } 1 \\
\text { Screw loosening: } 1\end{array}$ & $\begin{array}{l}\text { Hughston criteria } \\
\text { (good: 12, fair: 4) }\end{array}$ \\
\hline $\begin{array}{l}\text { Charapattanakom } \\
\text { et al. }{ }^{3)}\end{array}$ & 10 & & $\begin{array}{l}\text { Grade A: } 2 \\
\text { Grade B: } 8\end{array}$ & & $85-100$ & & & & & & $0.4-1.0$ & & \\
\hline \multicolumn{14}{|l|}{ Arthroscopic } \\
\hline \multirow[t]{2}{*}{ Zhao et al. ${ }^{7)}$} & 29 & & & & $93-100$ & & Grade 1: 1 & & & & $0-4$ & LOM: 6 & \\
\hline & & & & & & & Negative: 28 & & & & & Metal irritation: 1 & \\
\hline \multirow[t]{2}{*}{ Huang et al. ${ }^{5)}$} & 18 & & Grade A: 16 & & & & & & & & $0-5$ & LOM: 2 & \\
\hline & & & Grade B: 2 & & & & & & & & & & \\
\hline \multirow[t]{2}{*}{ Gui et al..$^{8)}$} & 24 & & Grade A: 20 & & $92-100$ & & Grade 1: 1 & & & & $0-3$ & LOM: 4 & \\
\hline & & & Grade B: 4 & & & & Negative: 23 & & & & & & \\
\hline \multirow[t]{3}{*}{ Chen et al. ${ }^{9)}$} & 36 & & Grade A: 33 & & $80-100$ & & & & & & $0-3$ & & \\
\hline & & & Grade B: 33 & & & & & & & & & & \\
\hline & & & Grade C: 3 & & & & & & & & & & \\
\hline \multirow[t]{2}{*}{ Chen et al. ${ }^{10)}$} & 22 & & Grade A: 21 & & $85-96$ & & Negative: 22 & & & & $0-2$ & & \\
\hline & & & Grade B: 1 & & & & & & & & & & \\
\hline \multicolumn{14}{|l|}{ Comparative } \\
\hline \multicolumn{14}{|l|}{ Sabat et al. ${ }^{12}$} \\
\hline \multirow[t]{3}{*}{ Open } & 27 & & Grade A: 25 & & & & & & & & $0-4$ & LOM: 3 & \\
\hline & & & Grade B: 25 & & & & & & & & & Revision: 1 & \\
\hline & & & Grade C: 2 & & & & & & & & & $\begin{array}{l}\text { Remvoal operation due } \\
\text { to irritation: } 2\end{array}$ & \\
\hline \multirow[t]{3}{*}{ Arthroscopic } & 20 & & Grade A: 18 & & & & & & & & $0-4$ & LOM: 1 & \\
\hline & & & Grade B: 18 & & & & & & & & & & \\
\hline & & & Grade C: 2 & & & & & & & & & & \\
\hline \multicolumn{14}{|l|}{ Pardiwala et al. ${ }^{16)}$} \\
\hline Open & 25 & & Grade A: 21 & & & & Negative :18 & & & & 3.9 & LOM: 3 & \\
\hline & & & Grade B : 4 & & & & Grade 1: 5 & & & & & & \\
\hline & & & & & & & Grade 2: 2 & & & & & & \\
\hline Arthroscopic & 25 & & Grade A: 22 & & & & Negative : 17 & & & & 4.1 & LOM: 1 & \\
\hline & & & Grade B: 3 & & & & Grade 1: 7 & & & & & & \\
\hline & & & & & & & Grade 2: 1 & & & & & & \\
\hline
\end{tabular}

IKDC: International Knee Documentation Committee, Postop: Postoperative, Preop: preoperative, LOM: limitation of motion.

Committee (IKDC) at final follow-up, (3) posterior draw test on physical examination, and (4) side-to-side difference on KT-2000 at final follow-up.

\section{Results}

\section{Literature Search}

The electronic search initially identified 1,092 articles. Critical application of the inclusion and exclusion criteria subsequently reduced that number to $12 ; 5$ studies on open posterior approach, 5 studies on arthroscopic fixation, and 2 directly comparative studies of the open posterior approach and arthroscopic fixation. The search strategy is outlined in Fig. 1, and an overview of the study characteristics is presented in Table 4. 


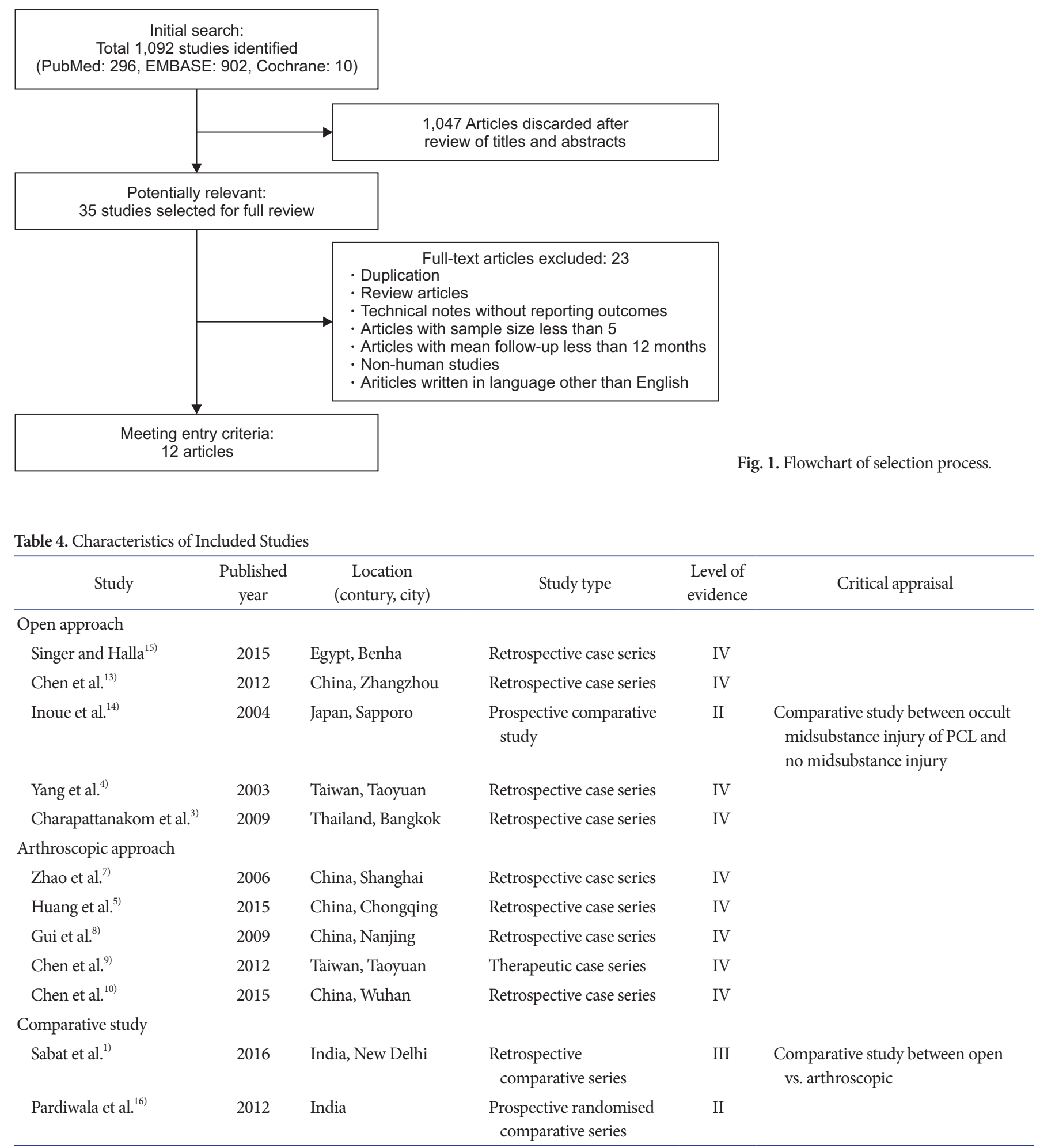

PCL: posterior cruciate ligament.

\section{Quality Assessment}

methodology score ${ }^{12)}$ for each criterion is shown in Table 5.

The mean modified Coleman methodology score of the included studies was $73.4 \pm 8.1$ (range, 61 to 89 ). The mean Coleman 


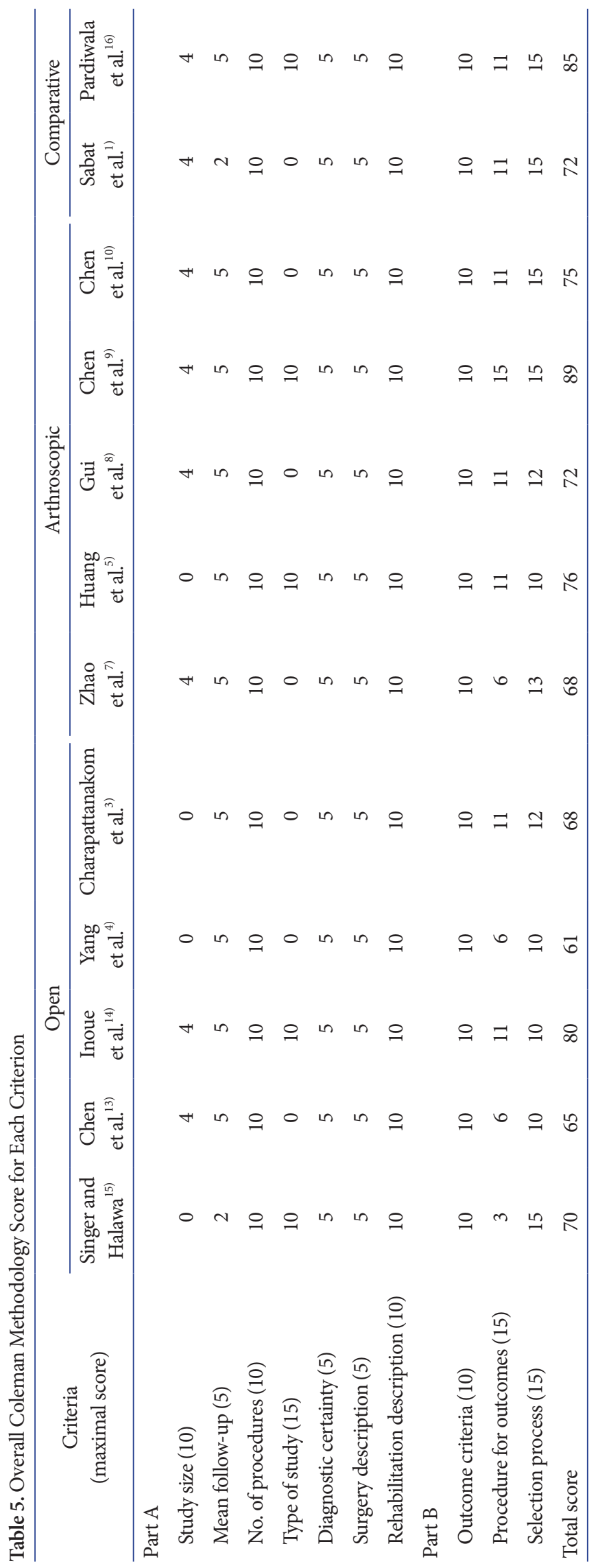

\section{Data Abstraction}

1) Surgical approach and technique

(1) Open posterior approach

Five studies and 2 comparative studies reported the outcomes of patients undergoing the open posterior approach ${ }^{13,4,13-16)}$. Overall, 134 patients underwent the open posterior approach with a minimum 12-month follow-up. Open posterior approach included the traditional open posterior approach and its modifications.

(2) Direct posterior approach

The traditional open posterior approach was originally described by Abbott and Carpenter ${ }^{4,17,18)}$. It is a direct posterior approach using the interval between the heads of the medial and lateral gastrocnemius muscles, and it requires the identification and protection of the tibial nerve, artery, and vein. However, division of the medial head of the gastrocnemius is commonly recommended to enhance exposure of the PCL avulsion, which could lead to postoperative weakness of this muscle and may unnecessarily increase the morbidity of the operation. The traditional open posterior approach was performed in 2 of the included studies ${ }^{4,14)}$.

Yang et al. ${ }^{4)}$ used this approach in 18 patients including 2 chronic cases. Inoue et al. ${ }^{14)}$ used the direct posterior approach although a modified posteromedial approach, described by Burks and Schaffer ${ }^{19)}$, was also used in the study without specific description of the proportion. Among its modifications, Chen et al. ${ }^{13)}$ suggested that the direct posterior approach under macroendoscopic assistance through a single minimal incision by a posterior midline approach is feasible for reduction of fragments and screw fixation.

(3) Posteromedial approach

The posteromedial approach was introduced by Burks and Schaffer ${ }^{19)}$ because of the complexity of the direct posterior approach and the need for dissection of the neurovascular bundle in the popliteal fossa. An interval between the medial border of the gastrocnemius and the semimembranosus tendon is used to expose the posterior joint capsule. This minimally invasive approach provides satisfactory exposure of the fracture site in a safe, simple, and less time-consuming manner for treatment of PCL injuries. Among the studies included in our analysis, this approach was used by Chiarapattanakom et al. ${ }^{3)}$ and Pardiwala et al. $^{16)}$ (in their open group). It avoids dissection of the neurovascular structures in the popliteal fossa as well, but it does not provide 
adequate exposure to the lateral base of the PCL and the capsule. The mass of the retracted tissue makes it difficult to place a screw perpendicular to the fracture plane, which could potentially lead to less stable fixation.

\section{(4) Modified posteromedial approach}

Other authors used a modified posteromedial approach, which splits the fibers of the medial gastrocnemius muscle to expose the PCL avulsion fracture. The lateral half of the fibers could protect the neurovascular elements in the popliteal space. This approach is anatomic and saves the medial head. Among the included studies, Singer and Halawa ${ }^{15)}$ and Sabat et al. ${ }^{1)}$ (in their open group) used this approach.

\section{(5) Arthroscopic fixation}

Five studies and two comparative studies reported the outcomes of the arthroscopic approach ${ }^{1,5,7-10,16)}$. Overall, 174 patients underwent the arthroscopic approach with a minimum 12-month follow-up.

Even though fracture reduction was done arthroscopically in all studies, each fixation method was different. Zhao et al. ${ }^{7)}$ made a Y-shaped bone tunnel and fixed the pull-out suture with a titanium button. Three articles (including one comparative study) described fixation was achieved using a pull-out suture through double tunnels ${ }^{9,10,16)}$. Gui et al. ${ }^{8)}$ performed pull-out suture fixation through a single tunnel. Huang et al. ${ }^{5}$ introduced antegrade screw fixation using a PCL guide after arthroscopic fracture reduction. It was selectively performed for patients with a fragment size larger than $20 \mathrm{~mm}$.

\section{Clinical Outcomes}

\section{1) Lysholm score}

Lysholm scores were used for subjective outcomes in 9 studies (4 studies on posterior open approach ${ }^{3,13-15)}, 4$ on arthroscopic approach $^{7-10)}$, and 1 comparative study ${ }^{16)}$ ). The scores at final follow-up were analyzed. The range of Lysholm score at final follow up was 85-100 for the open approach and 80-100 for the arthroscopic approach.

\section{2) International Knee Documentation Committee}

IKDC evaluation was used to determine subjective outcomes in 9 of the studies ( 3 studies on posterior open approach ${ }^{3,13,15}$ ) 4 on arthroscopic approach ${ }^{5,8-10)}$, and 2 comparative studies $\left.{ }^{1,16)}\right)$. The rates of normal and nearly-normal knees at final follow-up were analyzed. The rates were $92 \%-100 \%$ in patients with the open approach and $90 \%-100 \%$ in patients with the arthroscopic approach.

\section{3) KT-2000}

The side-to-side differences at final follow up on the KT-2000 were measured in 10 studies ( 3 studies on posterior open approach $^{3,13,14)}, 5$ on arthroscopic approach ${ }^{5,-10)}$, and 2 comparative studies $^{1,16)}$ ). At the final follow-up, the range of side-to-side difference was $0-5 \mathrm{~mm}$ irrespective of the approach.

\section{4) Complications}

There were no neurovascular injuries or compartment syndrome in both groups. There was one case of deep infection in the open approach group ${ }^{4}$. Limitation of motion was noted in 6 cases in the open approach group ${ }^{1,16)}$ and in 14 cases in the arthroscopic approach group ${ }^{1,5,7,8,16)}$. Four patients in the open approach group experienced reduction loss (2 cases) or metal irritation $(2 \text { cases })^{1,4)}$. One patient in the arthroscopic approach group experienced metal irritation.

\section{Discussion}

The most common mechanism underlying PCL avulsion fractures of the tibia in road traffic accidents is dashboard collision in which a direct force is applied to the proximal part of the tibia in an anteriortoposterior direction, with the knee in flexion ${ }^{20,21)}$. If left untreated, the injury leads to secondary joint changes resulting in osteoarthritis ${ }^{2)}$. Fixation methods for avulsion fractures of the PCL at the tibial insertion have been suggested in various series ${ }^{1,3-5,7-10,13-16)}$. This systematic review described outcomes and complications of the open approach and arthroscopic approach for displaced PCL avulsion fractures.

Two important aspects emerged from this study. First, there were only two direct comparative studies between the open approach and arthroscopic approach for displaced PCL avulsion. The included studies showed significant heterogeneity with various surgical techniques, fixation devices, sizes of fracture fragments, and follow-up periods; therefore, we could not compare the 2 approaches using statistical methods or determine the comparative superiority. Second, all studies on the open approach and arthroscopic approach for displaced PCL tibial avulsion fractures showed satisfactory outcomes, despite significant heterogeneity.

Regarding knee outcomes, the postoperative scores at final follow-up were analyzed. The range of Lysholm score at final followup was to 85-100 for the open approach and 80-100 for the arthroscopic approach. There was no noticeable difference between 
the 2 groups in regards to postoperative Lysholm scores. The rates of normal and nearly-normal knees at final follow-up were $92 \%-100 \%$ in patients with the open approach and 90\%-100\% in patients with the arthroscopic approach in the IKDC subjective knee assessment at final follow-up. All studies on the open approach and arthroscopic approach for displaced PCL tibial avulsion fractures showed satisfactory outcomes.

The comparison of the complication rates between open and arthroscopic treatments showed that the open procedures produce fairly superior results. Four patients in the open approach group experienced reduction loss (2 cases) and metal irritation (2 cases ${ }^{1,4)}$. One patient in the arthroscopic approach group experienced metal irritation ${ }^{7}$. There was one case of deep infection in the open approach group ${ }^{4}$. There were no neurovascular injuries or cases of compartment syndrome in both groups. Limitation of motion was the main complication for the open posterior approach group and arthroscopic approach group. It was noted in 6 cases in the open approach group ${ }^{1,16)}$ and in 14 cases in the arthroscopic group ${ }^{1,5,7,16)}$, more frequently in the arthroscopic approach group. The number of patients experiencing arthrofibrosis in the open approach group was less than half the number in the arthroscopic approach group. This result is contrary to our expectation and those reported in the 2 comparative studies where there were 3 cases of arthrofibrosis in the open posterior approach group and 1 case of arthrofibrosis in the arthroscopic group. This is presumably due to the fact that the open posterior approach exposes the avulsion fracture and fixes only the fracture fragment without the surrounding tissue being trapped.

Limitations of this systematic review should be noted. First, no randomized controlled trial was included in the analysis. Most articles were written with a focus on surgical techniques and reported the outcomes of a retrospective series. Moreover, the included studies showed significant heterogeneity, with various surgical techniques, graft types, and follow-up periods; therefore, we could not compare the 2 techniques using statistical methods or determine which surgical procedure was better. Second, there were only two studies directly comparing outcomes of the open posterior approach and arthroscopic fixation. Although singlearm case series were included to support the comparative studies, there is possibility that the pooled analyses are biased. Third, there was significant heterogeneity among operative techniques; to address the heterogeneity, we categorized the techniques. Fourth, all but one Egyptian paper are articles from Asian countries; articles from Europe or America are not included, and thus the reported results might not be generalized to other races.

\section{Conclusions}

All studies on the open posterior approach and arthroscopic fixation for displaced PCL avulsion fractures showed satisfactory outcomes, despite significant heterogeneity among studies with various surgical techniques, fixation devices, sizes of fracture fragments, and follow-up periods.

\section{Conflict of Interest}

No potential conflict of interest relevant to this article was reported.

\section{Acknowledgments}

We thank Na-Jin Kim (Medical Librarian; Medical Library, The Catholic University of Korea, Seoul, Korea) for her support with the literature search.

\section{References}

1. Sabat D, Jain A, Kumar V. Displaced posterior cruciate ligament avulsion fractures: a retrospective comparative study between open posterior approach and arthroscopic singletunnel suture fixation. Arthroscopy. 2016;32:44-53.

2. Strobel MJ, Weiler A, Schulz MS, Russe K, Eichhorn HJ. Arthroscopic evaluation of articular cartilage lesions in posterior-cruciate-ligament-deficient knees. Arthroscopy. 2003;19: 262-8.

3. Chiarapattanakom P, Pakpianpairoj C, Liupolvanish P, Malungpaishrope $\mathrm{K}$. Isolated $\mathrm{PCl}$ avulsion from the tibial attachment: residual laxity and function of the knee after screw fixation. J Med Assoc Thai. 2009;92 Suppl 6:S181-8.

4. Yang CK, Wu CD, Chih CJ, Wei KY, Su CC, Tsuang YH. Surgical treatment of avulsion fracture of the posterior cruciate ligament and postoperative management. J Trauma. 2003; 54:516-9.

5. Huang W, Gong X, Rahul M, Priyanka S, Wang C, Liang X, Ding G, Hu N. Anterior arthroscopic-assisted fixation of posterior cruciate ligament avulsion fractures. Eur J Med Res. 2015;20:88.

6. Gwinner C, Hoburg A, Wilde S, Schatka I, Krapohl BD, Jung TM. All-arthroscopic treatment of tibial avulsion fractures of the posterior cruciate ligament. GMS Interdiscip Plast Reconstr Surg DGPW. 2016;5:Doc02.

7. Zhao J, He Y, Wang J. Arthroscopic treatment of acute tibial 
avulsion fracture of the posterior cruciate ligament with suture fixation technique through Y-shaped bone tunnels. Arthroscopy. 2006;22:172-81.

8. Gui J, Wang L, Jiang Y, Wang Q, Yu Z, Gu Q. Single-tunnel suture fixation of posterior cruciate ligament avulsion fracture. Arthroscopy. 2009;25:78-85.

9. Chen SY, Cheng CY, Chang SS, Tsai MC, Chiu CH, Chen AC, Chan YS. Arthroscopic suture fixation for avulsion fractures in the tibial attachment of the posterior cruciate ligament. Arthroscopy. 2012;28:1454-63.

10. Chen LB, Wang H, Tie K, Mohammed A, Qi YJ. Arthroscopic fixation of an avulsion fracture of the tibia involving the posterior cruciate ligament: a modified technique in a series of 22 cases. Bone Joint J. 2015;97:1220-5.

11. Sasaki SU, da Mota e Albuquerque RF, Amatuzzi MM, Pereira CA. Open screw fixation versus arthroscopic suture fixation of tibial posterior cruciate ligament avulsion injuries: a mechanical comparison. Arthroscopy. 2007;23:122630 .

12. Coleman BD, Khan KM, Maffulli N, Cook JL, Wark JD. Studies of surgical outcome after patellar tendinopathy: clinical significance of methodological deficiencies and guidelines for future studies: Victorian Institute of Sport Tendon Study Group. Scand J Med Sci Sports. 2000;10:2-11.

13. Chen W, Tang D, Kang L, Ding Z, Sha M, Hong J. Effects of microendoscopy-assisted reduction and screw fixation through a single mini-incision on posterior cruciate ligament tibial avulsion fracture. Arch Orthop Trauma Surg.
2012;132:429-35.

14. Inoue M, Yasuda K, Kondo E, Saito K, Ishibe M. Primary repair of posterior cruciate ligament avulsion fracture: the effect of occult injury in the midsubstance on postoperative instability. Am J Sports Med. 2004;32:1230-7.

15. Singer MS, Halawa AM. Minimally invasive open reduction and fixation of avulsed tibial insertion of posterior cruciate ligament. Eur Orthop Traumatol. 2015;6:357-61.

16. Pardiwala DN, Agrawal D, Patil V, Saini U, Dhawal P. Paper 133: comparison of open versus arthroscopic fixation for isolated PCL tibial bony avulsions: a prospective randomized study with minimum 2 year follow-up. Arthroscopy. 2012; 28(9 Suppl):e413-4.

17. Abbott LC, Carpenter WF. Surgical approaches to the knee joint. J Bone Joint Surg. 1945;27:277-310.

18. Trickey EL. Injuries to the posterior cruciate ligament: diagnosis and treatment of early injuries and reconstruction of late instability. Clin Orthop Relat Res. 1980;(147):76-81.

19. Burks RT, Schaffer JJ. A simplified approach to the tibial attachment of the posterior cruciate ligament. Clin Orthop Relat Res. 1990;(254):216-9.

20. Janousek AT, Jones DG, Clatworthy M, Higgins LD, Fu FH. Posterior cruciate ligament injuries of the knee joint. Sports Med. 1999;28:429-41.

21. Schulz MS, Russe K, Weiler A, Eichhorn HJ, Strobel MJ. Epidemiology of posterior cruciate ligament injuries. Arch Orthop Trauma Surg. 2003;123:186-91. 